\title{
Participating in the Digital Society
}

\author{
ÅKE GRÖNLUND, School of Business, Örebro University, Örebro, Sweden
}

\begin{abstract}
Many signs today indicate a decline of both democracy and trust in the Internet and social media. This seems to make digital democracy a hard sell. Furthermore, for digital democracy to be globally relevant, it is necessary to find ways to also make it useful in countries with less-democratic or even authoritarian regimes. This is where a majority of the world's population live and where improvements are most important for the world to become more democratic.

Drawing on the concept of "citizen participation" [Almond and Verba 1963] and the Information System Artefact model [Lee et al. 2015], we discuss how participation can be improved in countries of any regime in terms of the technology used, the information flows, and the social systems in which technology and information are used to communicate. Examples from Sweden and Uganda, countries with very different regimes, illustrate how improvements can be made everywhere, however, only with considerable effort.

The main conclusion is that democracy is not something you have but rather something you do. It has to be implemented every day, mostly in small steps and often in the context of administration rather than politics. Because such contexts occur also in authoritarian countries, technology can be used to improve participation everywhere.
\end{abstract}

CCS Concepts: • Applied computing $\rightarrow$ Computing in government; E-government;

Additional Key Words and Phrases: Digital democracy, citizen participation, information system artefact, trust

ACM Reference format:

Åke Grönlund. 2020. Participating in the Digital Society. Digit. Gov.: Res. Pract. 1, 2, Article 17 (April 2020), 13 pages.

https://doi.org/10.1145/3361865

\section{INTRODUCTION}

The field of digital (or e-) democracy today, and for a long time, lives a rather obscure life in the outskirts of neighboring research fields, with digital (or e-) government being the most obvious field of growth. Given the past several years' development toward mistrust in both democracy and the Internet, primarily social media, and the general decline of democracy observed [Lührmann et al. 2018], spearheading digital democracy may seem increasingly difficult.

This makes it an even more important task for everyone who believes technology can help improve democracy. Therefore, in looking back and forward this article aims at pointing toward some opportunities.

To understand what to improve we must first look at factors defining democracy. Following the main observers [EIU 2018], we include not only electoral processes but also a conducive social environment, including civil liberties, participation, political culture, and the functioning of government.

Author's address: Å. Grönlund, School of Business, Örebro University, Ȯrebro, Sweden; email: ake.gronlund@oru.se.

Permission to make digital or hard copies of all or part of this work for personal or classroom use is granted without fee provided that copies are not made or distributed for profit or commercial advantage and that copies bear this notice and the full citation on the first page. Copyrights for components of this work owned by others than ACM must be honored. Abstracting with credit is permitted. To copy otherwise, or republish, to post on servers or to redistribute to lists, requires prior specific permission and/or a fee. Request permissions from permissions@acm.org.

(c) 2020 Association for Computing Machinery.

2639-0175/2020/04-ART17 \$15.00

https://doi.org/10.1145/3361865

Digital Government: Research and Practice, Vol. 1, No. 2, Article 17. Publication date: April 2020. 


\section{7:2 • A. Grönlund}

Next, we look at artefacts. The artefacts we build to assist us make our social world firmer, because they formalize parts of our behavior. The design of artefacts is important, because they not only support but also direct and restrict our behavior. Digitalization changes our artefacts. Because design of artefacts happens through social processes, we have the opportunity to affect the design. This means the field of digital democracy must pay attention to all the artefacts involved in defining the processes of democracy within this broad definition.

This is a challenge for research, as many relevant artefacts and processes are found outside the contexts usually presented in journals and conferences on digital democracy. There is some domain competition among fields like digital government, media studies, political science, computer science, and others, and many issues fall between chairs as researchers generally tend not to stray too far from the core of their own field.

We discuss some of the artefacts that have emerged within the field of digital democracy using the lens of the Information System Artefact model [Lee et al. 2015], which comprises three different but integrated sub-artefacts: a technical, an informational, and a social.

Empirically, this article is anecdotal. Some empirical examples are used to discuss a view of democracy and participation in the digital society that is not limited to the formal decision-making processes but puts more focus on the environment for this decision making, the soil in which democracy grows (or withers). The point to be made is that democracy is a participatory approach to societal decision making. Participation can be strengthened and make a positive difference in any country, not just those that have a formal democratic system. Participation can also be undermined and reduced in any country, including those who are long-standing formal democracies. Participatory decision making grows only in societies where participation is nurtured. Therefore, it is important to work to increase and improve participation in every country.

An implication for the research field of digital democracy is that it is important to consider participatory aspects of the use of information systems in a wide range of pertinent contexts not to limit research to specific processes of formal democracy.

\section{DEMOCRACY}

Many of the discussions that have formed the field of digital democracy concern formal democratic decision making, but we know of many countries where democracy is dysfunctional, even though formal arrangements, such as voting and parliaments, are in place.

Taking a comprehensive view of democracy, the Economist Intelligence Unit (EIU) democracy index [EIU 2018] considers five categories of issues: electoral process and pluralism, civil liberties, functioning of government, political participation, and political culture. Measured by that index, in 2018 only 20 nations $-10 \%$ of the countries in the world-were assessed as "full democracies." A further 55 were considered "flawed democracies," which have free and fair elections and where basic civil liberties are honored but where there are issues with, for example, media freedom, an "underdeveloped" political culture, low levels of participation in politics, or the functioning of governance. The remaining 92 countries in the study, which encompassed 167 of the world's currently 193 states, are authoritarian or "hybrid."

Another measure of the situation is that only $4.5 \%$ of the world's population lives in full democracies, $43.2 \%$ in flawed democracies, and the rest (52.3\%) under authoritarian or "hybrid" regimes. In authoritarian countries, there is typically no free press and limited freedom of speech and assembly, in many cases combined with a strong repressive system for controlling individuals, which makes any attempt to express political views hazardous.

The decimals of those numbers can be argued, as can the details of the investigation. But it is beyond doubt that a large proportion of the world's population live in countries where the preconditions for participating in democratic processes are nowhere near meeting the basic standards for any citizen to dare participate, even if there were formal procedures available-which there are in many such countries.

According to the Wikipedia National Election Calendar [Wikipedia 2019b], there are only about a dozen countries that do not have direct elections for a national legislative body but at least 147, as of the EIU, which are not full democracies.

Digital Government: Research and Practice, Vol. 1, No. 2, Article 17. Publication date: April 2020. 
While certainly the details of the formal democratic decision-making systems are also important in the 20 full democracies, given this situation it seems more important to make use of technology to improve the preconditions for democracy in every country in the world. The formal democratic decision system will only be a facade anyway if the surrounding social system does not at least meet decent standards regarding the EIU democracy criteria.

Trust is the basic issue for participation at any level. For everybody except a daring few, to write political articles or even air any criticism toward government in a newspaper or in social media, you must trust the government not to imprison you, or punish you in any other way, for doing so.

Participating in a government-arranged consultation on a contested political issue probably only takes place in countries with stable democratic systems, so participants' personal safety will probably not be at stake, but to make it meaningful they must trust that government will seriously listen to the views expressed.

Seen from the other side, to guarantee a free press, governments must trust their citizens to express their views in a constructive manner without reference to violence or generally aiming at undermining social order. To arrange more in-depth discussions with citizens, such as consultations, governments must trust citizens to accept the eventual decision even though some people will be disappointed with it.

Trust is a critical issue today, as it seems to be in decline also in democratic countries. The World Values Survey found that only 19\% of Americans have faith in the government to do what is right "always or most of the time." Trust in the major actors on the Internet is also in decline. While it is difficult to find validated numbers for trust in, for example, Facebook, they are not going up [Richardson 2018]. Another sign of increased distrust in government is the growth of support for political parties and individual politicians whose programmes are disruptive and promise to take the UK out of the "tyranny" of the EU and "take back control," "drain the swamp" in Washington, and "throw out the foreigners."

There are many analyses of the various issues that pertain to the preconditions for democracy, including economy, social inclusion or exclusion, segregation, and more, but here we will focus on the use of technology to improve democracy.

Digitalization is only partially technical; more importantly, it involves changes in the social systems in which we live and work. Changes are due to new information flows both between people and between people and machines. The popular press often suggests that all the impetus for change comes from technology, but of course influence goes both ways. Information flows are changed, because some actors want it to happen and can use machines to do it. Changed information flows affect social systems, but changes in social systems also affect information flows.

Change is institutionalized in several ways: in laws and business models, of course, but also in the design of the artefacts we use. When everybody uses mobile phones, the fixed telephone network is successively dismantled or in some countries never even built. This means there is no way back, even though a fixed network has many advantages, for example, by being more robust than a wireless system.

A perhaps more drastic example is the recent problems with a Boeing 737, where an automated flight control system took over from the pilots, who could not take control back, with the result that the plane crashed [Wikipedia 2019a]. Artefacts and humans today compete for control, and this example shows that it is not necessarily clear that humans always win or even understand how important decisions were made by technology.

Our artefacts define our world. Therefore, the design of them is extremely important.

\section{ARTEFACTS}

The Information System Artefact (ISA) model [Lee et al. 2015] is often used in the field of social informaticsthe study of information and communication tools in cultural or institutional contexts [Kling et al. 2005; Kling 2007] - to link technology to social life. It draws on Herbert Simon's theory of the artificial, which theorizes the importance of artefacts and the design of them. 
Artefacts are important to us not just as "tools," like a hammer, but also more fundamentally as objects defining parts of our world. We do not just form artefacts, they also form us, our actions, and our thinking. The car and the airplane form our thinking about travel and distances.

Digital artefacts are yet relatively new to us, and we have not yet completely learned how to use all of them to the best advantage for us all. Social media is one example where both formal and informal rules and practices are still under development. We are uncertain about how to use them. The ways we use them have changed considerably over just a few years, and the issue of the function and role of social media platforms has scaled up from an issue of social behavior to become the core of an international conflict between big business and politics.

But even long-established artefacts, like cars, are still subject to changes both in terms of the rules for their use and our thinking about them due to new developments such as the strive for less energy consumption and less environmental damage.

The formal scientific discussion of the importance of the artefact originally stems from Herbert Simon's "Sciences of the Artificial," where the design of artefacts is in focus [Simon 1996]. While natural sciences are concerned with "what is," design is concerned with what "ought to be." Artefacts are designed not by nature but by humans. The design is not a one-shot affair but evolves over time through the influence from the users of the artefacts. But artefacts also shape our minds. Once in place, they institutionalize our thinking, not only that of today but also-often primarily-that of yesterday.

On that line of thinking, the concept of the ISA conceptualizes digital artefacts and their development [Lee et al. 2015]. An ISA is defined as comprising three integrated and equally important parts, sub-artefacts, which evolve together and each of which each is subject to human design. The technology artefact concerns the digital tools that serve a purpose in a particular process or situation. The information artefact concerns the occurrences of communication that involve an exchange of data that makes meaning to the participants. The social artefact concerns the interactions among individuals involved in the process at hand.

An artefact need not be a physical object; it may also be a rule system defining human action, such as laws, or a method, such as processes in court.

This is a useful model, as it shifts the focus from technology itself to also include the contexts in which it is designed and used. Technologies do not appear out of the blue; any technology is shaped by its use over time. In the context of digital democracy, the three parts of the ISA concern different aspects of both democracy and technology.

The information artefact concerns how we handle information in processes pertinent to democracy, where a number of questions need to be considered. What information will people need to be able to participate? What information is gathered and communicated? How is information collected, analyzed, processed, and passed on from those who have it to those who need it? And to whom, in what form, and when? How is information designed so as to be functional in the use context?

The social artefact concerns how processes related to democracy are organized, both formal and informal ones. Formal artefacts may include voting, meeting procedures, debates, procedures for making proposals, and more. Informal artefacts may include partially formal ones like media (which are given a democratic role by law but whose actions are not strictly regulated) and more informal ones like social media, social gatherings in general, and ad hoc encounters between voters and politicians. As we shall see, all these processes can shift in the degree of formality, and one of the most interesting aspects of technology is that it allows for, and even encourages, such shifts. This is important, because the degree of formality of a process affects both the access to it and the outcome of it.

The technology artefact has some properties of its own that influence its use, such as usability, processing capacity and speed, technical robustness, security, and so on. But in general, digital technology is malleable and lends itself to an enormous variety of social and informational processes and degrees of formality. This means that technology design can be adapted to changes in the other two subsystems. While there are restrictions due

Digital Government: Research and Practice, Vol. 1, No. 2, Article 17. Publication date: April 2020. 
to the inherent characteristics of technology, it is in no way determining the design of the social and information artefacts.

\section{DIGITAL DEMOCRACY ARTEFACTS}

The debate on digital or e-democracy around the turn of the millennium was about improving the formal democratic system in different ways using the then-emerging World Wide Web. There were three broad categories of activities discussed-information, consultation, and voting-all of which are involved in democratic processes but that can be designed in a great number of ways depending not only on technology but very much on ideology.

There were a number of different theories of democracy at play at the time. Two of the poles in the theoretical field included the mainstream representative democracy and deliberative or participatory democracy, sometimes called "strong," referring to its mission to engage more people in active decision making [Barber 1984; Pateman; 1976; Arnstein 1969]. One further type awakened by the technical development was what has been called "quick" democracy, referring to the extensive use of polls for the purpose of more quickly informing politicians about "the people's preferences" [Åström 2001] and extensive use of technology to inform the people about political issues to be polled upon. Direct democracy was a fourth pole sometimes popping up in the debate, suggesting that the polls at times should turn into referendums with decision-making power.

Around the turn of the millennium, the digital democracy field saw the development of a number of (partly) digital artefacts designed to serve one or more of these ideas of the desired model of democracy.

Information on the Internet concerned various ways the Internet could help in making democracy more visible to citizens. Examples included making documents relevant to political decision making available online, streaming city councils' meetings, and so on. While information is important to any kind of democracy, different artefacts were designed for different purposes. Streaming city council meetings means creating a social artefact; it makes individual politicians more visible than if city council meeting minutes are only made easily available on the Internet. In some cases, there was also a slot where questions from the public were allowed, which makes the artefact even more social. The more social the artefact, the more it fits in with the ideal of "strong" democracy.

The most social of the digital democracy artefacts is the consultation. This has come about in many forms and under many names, including but not limited to digital town hall meetings, citizen juries, e-petitioning, and simply consultation. A consultation was often designed explicitly for "strong" democracy, although there were more neutral forms, like e-petitioning, which could include a social component at the stage of composing them but still fitted in with representative democracy as they did not directly involve decision making.

The consultations designed for deliberation and decision making were built on more or less formalized formats for decision-making processes. Several methods for creating consensus were devised and implemented in digital tools. A number of companies built around such methods and tools appeared. Here in Sweden there were at least five such tools that were built on different decision-making processes and used different technologies [Grönlund 2001].

Online voting is primarily a technical artefact, but it can be used in different democratic contexts, which makes it social in very different ways. In the early days of digital democracy, the use of it was primarily discussed in view of representative democracy even though some new parties that may be called experimental popped up and aimed at using it for direct democracy purposes.

Several companies created systems for online voting and there were minor trials in experimental settings, e.g., a Swedish student union election in 2002 with technology from the US company Safevote [Grönlund and Hällgren 2002; Ohlin and Hällgren 2002]. Privacy problems that cannot be solved by technical means made voting from home incompatible with the principle of secret voting, and today it is only in Estonia that online voting is used. Digital voting in polling stations is a very different matter in this respect and has since become frequently used in many places. One reason is that it can help make vote counting more reliable and hence potentially improve existing manual procedures. 
Table 1. Democracy-related Activities (Score from Sweden, Applies in Various Degree to Other Countries)

\begin{tabular}{|c|c|c|}
\hline Activity & 1999 & 2019 \\
\hline \multicolumn{3}{|l|}{ Information } \\
\hline $\begin{array}{l}\text { Learn about any MP's views online, in writing, } \\
\text { audio or video }\end{array}$ & & $\mathrm{X}$ \\
\hline $\begin{array}{l}\text { Gain comprehensive information about any } \\
\text { political party's views online, in writing, audio } \\
\text { or video (directly, not mediated by press or TV) }\end{array}$ & & $\mathrm{X}$ \\
\hline $\begin{array}{l}\text { Learn about the parliament's (local or national) } \\
\text { agenda and decisions online (directly, not } \\
\text { mediated by press or TV) }\end{array}$ & & $\mathrm{X}$ \\
\hline $\begin{array}{l}\text { Learn about/investigate/find legislation of } \\
\text { relevance to you-existing and proposed-online }\end{array}$ & & $\mathrm{X}$ \\
\hline \multicolumn{3}{|l|}{ Communication } \\
\hline Email any MP & & $\bar{X}$ \\
\hline Email any MP and receive a response & & $\mathrm{X}$ \\
\hline Email any political party and receive a response & & $\mathrm{X}$ \\
\hline \multicolumn{3}{|l|}{ Participation } \\
\hline Participate in an online consultation & $\begin{array}{l}\text { Only in a few cities, and } \\
\text { typically just in an experiment }\end{array}$ & $\begin{array}{l}\text { Locally and internally } \\
\text { in some organizations }\end{array}$ \\
\hline $\begin{array}{l}\text { Participate in an online discussion where a } \\
\text { politician is present }\end{array}$ & & $\mathrm{X}$ \\
\hline Vote online & & Only in Estonia \\
\hline
\end{tabular}

In terms of the ISA model, these different artefacts are more or less social and more or less structured in terms of their information handling and involve more or less advanced technology.

E-voting may be seen as mainly a technology artefact in that security, integrity, and preserving privacy are crucial for the credibility of the voting process, but as it can be used both in representative, deliberative, and direct democracy, it can assume different social roles.

The consultation is predominantly a social artefact as the purpose is engaging people, preferably in large numbers, in debating and decision making. But as the number of participants grows, consultation also requires advanced technology and formalized procedures to meet the standards for democratic debate.

Information provided to the public is the least technically demanding artefact, as it concerns digitizing documents and making them available. But then there are the issues of what information, available how (e.g., by push or pull), when (at which point in the decision-making process?), organized how (how can information and relations between different information objects be found?), and in what format (e.g., city council minutes online or streamed meetings), which makes also the information artefact a complicated matter of design subject to a discussion of what kind of democracy is desired to be created.

Comparing the situation 20 years ago to that of today in terms of what we as citizens can do online in terms of democracy-related government contacts, at first glance it looks quite promising (Table 1). Many activities have moved from an experimental stage to the mainstream over that period.

Today, we take the availability of all these activities for granted, but in the history of democracy these information and communication channels are new, and they have in many ways contributed to reducing the distance between politicians and voters. Not only for the better, however; tweeting has made many politicians' thoughts immediately available to many people, but this has not necessarily improved political communication. 
But these things are part of a changed context. Democracy is different now. The world is different in many ways. Migration, automation, globalization, poverty reduction, climate change, terrorism, changed wealth distribution, and other big issues have contributed to the development of technology in directions that do not necessarily fit comfortably with the digital democracy discussions of 20 years ago.

\section{CHANGE IN CONTEXT}

In terms of the ISA model, current mainstream technological development can briefly be characterized as follows.

Information artefacts have developed in ways that focus on individual use and control. Twitter is principally for propagating individuals' views. Even though it is possible to respond there, it is no social arena for deliberation. On the contrary, such artefacts have turned into large-scale platforms for personal expression (and reactions to that) and sometimes fake news. On the commercial side, the main platforms are primarily concerned with collecting information from their users to be able to sell advertisements. Discussion is possible but as people tend to gather in the company of the like-minded, groups often reinforce already-existing views and communities rather than deliberate on different views.

Governments have created a large number of information artefacts online where enormous amounts of government information can be accessed and used by citizens. Most of that information is also designed for individuals, for their own information and to make it possible for them to manage to serve themselves in dealings with government.

Social artefacts have developed in a number of directions. Social media artefacts are primarily designed for individual use, not for deliberation and discussions leading to people forming shared opinions. Tools like commenting and liking offer a poor environment for structured, goal-oriented in-depth discussions. Not surprisingly, people with different views tend to end up in different social forums where their views are reinforced rather than challenged.

There is another, different, strong development of social artefacts primarily designed for professional use, including groupwork tools like Zoom, Adobe Connect, Google Hangout, and Skype. These are designed for discussion and deliberation and sometimes include fairly advanced features for sharing information, working on the same material, taking turns in discussions, and making decisions. These advanced cooperative features come at the cost of scale, and such tools can typically only cater for a limited number of users.

These mainstream developments broadly set the scene for government use of technology for democratic purposes. An enormous amount of relevant data can be, and has been, made available. People have become used to using technology not only for information retrieval but also for many kinds of social interaction. This includes for purposes related to democracy-if they dare and find it effective.

Let us look at a few examples where people participate using technology for achieving change in issues where politics and the public sector is involved. Two of the cases are from Sweden and three from Uganda-two countries at opposite ends of the EIU democracy ranking list. All cases concern political decision making only indirectly, but they all directly serve the purpose of building trust in society.

\subsection{Consultations for Participation}

Digitalizing school-but how? The Swedish Association of Local Authorities and Regions (SALAR) represents and advocates for all 290 municipalities (which range in size from 2,500 to 962,000) and 20 regions of Sweden. The Swedish government is decentralized, with many major national tasks delegated from central government. For example, the regional authorities are responsible for national healthcare and the local ones for schools. For both these things, national government is the regulator, but the local and regional authorities are in charge of organization and economy.

In 2017, the Swedish government set up a national digitalization strategy for the school sector. The plan was very general, and SALAR was charged with the task of operationalizing it.

Digital Government: Research and Practice, Vol. 1, No. 2, Article 17. Publication date: April 2020. 
The task was challenging, as it involved making digitalization develop in a similar way and with similar quality in municipalities of every size, encompassing quality issues, new work situations for teachers, and new costs for municipalities. The traditional way to produce an implementation plan would be to have strategic meetings with key stakeholders and perhaps a survey to municipalities, but because of the unusual degree of change involved, SALAR decided to ground the policy decision in a large-scale consultation. The consultation reached out not only to local school decision makers but also to professionals in the field: school principals, teachers, and researchers. Some 30 consultation meetings were held across the country. Most included a physical meeting with group discussions, and a few were only online. The physical ones gathered people in a certain region, and the online ones were open to anybody (after registration, participation was not anonymous). The physical ones included structured discussions in groups based on questions derived from the goals of the national digitalization strategy. Each group then posted their comments in a digital system whereupon they were visible for comments and voting by other participants. The process closely resembled the concept of town hall meetings, except the organizer was not a political organization but a professional one acting on behalf of government.

Altogether some 3,000 people took part and more than 1,000 proposals were received. We have not yet published the report on the consultation process, but one thing that is already clear is that it included a surprise. SALAR originally thought of the implementation plan as a top-down development where they would specify what the local school organizations would need to do to implement the strategy. The consultations clearly showed, however, that there was a need for many initiatives at the national level, things that only the national government could initiate and design. The SALAR National Roadmap [SKL 2019] of March 2019 thus includes 18 "initiatives," broad fields of action each comprising several tasks, of which at least 12 include direct requirements for national government to act.

This is an unusual outcome, and it was described as surprising. It appears that although the people taking part in the consultation were not directly involved in the decision-making process, their views and arguments had a strong effect on the report. Political decision making is still in the future, but the consultation seems to have made a difference in terms of giving politicians a basis for decisions they did not previously have.

In terms of the ISA model, this consultation meant major changes in the information and social artifacts but a minor change as regards the technical one. The investigator, SALAR, experienced a completely different information supply than the usual, as information was collected systematically and from an around 100-times-larger set of people compared to the traditional work model. The social artefact was also radically changed, as people were not just interviewed, as in the traditional work model, but could also form groups to discuss and formulate well-conceived proposals as well as vote on proposals from others so as to introduce an element of prioritization.

The technical artifact used was a digital democracy tool designed for more formal democratic procedures. It was chosen on merit, as it worked well in many earlier consultations of a more traditional kind. While it served well to collect information, it proved less useful for aggregating and analyzing it. For one thing, this shows that this consultation was of a kind that has not yet occurred to designers of digital democracy tools. This consultation was not directly political but involved more in the way of facts and analysis and less in terms of political ideology and confrontation. Politics was certainly involved as the input-the digital strategy was political, and the proposals would eventually be subject to political decisions-but the consultation itself was "pre-politics," and the people involved were professionals and managers, not politicians.

In terms of the factors defining democracy (see Section 2) this consultation is an attempt to improve the functioning of government by introducing a more participatory way of pursuing an innovation process at the strategic and tactical levels. It involved national and local government in cooperation, which is unusual. There is no way to objectively measure the result, but the fact that all parties involved were very satisfied with the new work model is an improvement in participation as it indicates an increase in trust.

Patients' rights in view of failed healthcare. In 2010 the Swedish government initiated a vaccination campaign aimed at curbing an emerging epidemic of swine flu. The campaign failed in that the vaccine was not sufficiently

Digital Government: Research and Practice, Vol. 1, No. 2, Article 17. Publication date: April 2020. 
tested, and a number of people contracted narcolepsy as a result of taking it [Erikson et al. 2019]. In Sweden, approximately 350 young people were affected [Blomberg et al. 2017]. The process of handling the results of that failure stretched over six years and led to two major political decisions and several technical investigations. The first decision was to formally acknowledge that the disease was actually caused by the vaccine. This initially required a technical investigation into chemistry and medicine and later a political process regarding what responsibility the government, who had decided to launch the vaccination campaign, had for the result. Once the causes of the disease were understood and the government had decided to assume responsibility, another political process that concerned compensation to those affected began.

Already by late 2009, at the outset of this long process, a Facebook group was started by parents of the affected children. The purpose of the group was to support people affected in many ways: to understand the disease and learn about treatments, to find support and comfort among people equally affected, and to lobby the government to take responsibility for the situation and compensate people for the circumstances they had to deal with after having contracted the disease. Narcolepsy is a very problematic disease that prevents people from leading a normal life. They cannot obtain a driving license, many jobs are not available to them, schoolwork becomes very difficult, and their social life is affected.

The group rapidly grew to just under 800 members, a number that includes all affected young people and about twice as many relatives (many of the affected were young children in 2010 and have joined the group later).

Throughout this six-year process-and still today-the Facebook group has been very active in discussing medical and social issues as well as government responsibility. The activity was unusually high for such a group. A majority (60\%) of the group took active part in discussions. Only $40 \%$ were lurkers, a number to be compared with the usual 90\%, according to the rule of thumb. The discussions in the group were investigated by Eriksson et al. [2019], who found that they were very factual and constructive and devoid of conspiracy theories and general mistrust of government, despite the serious situation and the strong feelings held by group members not only regarding having to deal with a very problematic and unexpected situation but also about being unfairly affected as the government had actively urged people to take the vaccination and specifically targeted children by setting up vaccination stations at schools.

There were no politicians in the group (at least not anyone openly identifying themselves as such), but the group was open, so anybody could follow the discussions. The group of affected people became a fairly powerful voice in the general debate, and this was no doubt partly due to the existence of this very active Facebook group. The people affected were distributed across the whole country. Sweden has 290 cities and municipalities distributed over some $450,000 \mathrm{~km}^{2}$, which means it would have been impossible to form an active group where discussions were ongoing every day without the Internet offering an easy-to-use tool.

The group was certainly not a formal consultation in the way such issues are discussed in the field of digital democracy, but it was a strong voice in the debate that led to what must be said to be, for the affected, more positive decisions on all points of discussion than what would probably have been the case without it. Despite considerable initial resistance, the government eventually assumed responsibility for the serious effects of the vaccination campaign and decided to pay life-long economic support to those affected.

These examples are Swedish, but similar initiatives can be found elsewhere-but certainly not anywhere. It takes a considerable measure of trust between government and citizens to make them happen.

In the examples, people who are not politicians had influence over political decision making by means of participation; not in the actual decision making but in the long processes forming the views and gathering the information needed for making informed and accepted political decisions.

In terms of the ISA model, the narcolepsy group is an example of a successful information system artifact that considerably extends the opportunities for the people involved to manage their problematic situation. The information artifact was a standard social media tool, and what made it work well was the way in which it was managed by the participants. In terms of the ISA model, the social artifact was robust enough to use the technical 
artifact well and to handle problems that occurred in the information artifact, such as when individuals offered conspiracy theories that had to be debunked.

Defining democracy in the EIU way (see Section 2) suggests that digital democracy should be about using ICT to not just improve participatory processes in decision making but also in information gathering and processing and in opinion-forming making for well-informed decisions in which people affected by the decisions have greater opportunities to participate. "Participating" in the genuine meaning of the word means not just being around but being able to affect decisions.

This view is consistent with the current discussion about participation [Åström 2019] and in line with the Almond and Verba [1963] definition of "citizen participation" to include activities by citizens that aim at influencing government by means of both institutional and non-institutional paths of influence.

As we saw in the section on democracy, the trust necessary for such participation is a far bigger problem from a global perspective than the problems of ticking off some of the formal democratic criteria like having a parliament and elections.

It seems reasonable to assume that increasing trust comes by means of small steps in environments where there already is some level of trust. Trust at a national level cannot be built without trust in local contexts.

In the SALAR case, the population involved were primarily professionals sharing, largely, a professional view of the issues at hand and respecting each other for their professionalism. The narcolepsy discussion forum not only included the people affected but also a community of trusted medical professionals from which most of the facts supporting the discussions came.

Both cases also show that "local" no longer means only geographically local. Both cases concern national issues and people from all over the country, but they are "local" in the sense that people with similar interests have come together to jointly work for a worthy cause.

Both cases also show that all three sub-artifacts of the ISA model are important. The social artifact is the most fundamental as it sets the scene for both the others. The technical artifact may sometimes be quite simple-the swine flu group used a standard Facebook group-but the SALAR case shows that there are areas for democratic participation that the digital democracy field has yet not recognized and developed tools for. For sustaining such a participatory work method, there is a need to improve the technical tools.

\subsection{Local Participatory Development}

So far, we have used the ISA artifact model to illustrate the relations between technology and people. For technology to be well used, the three aspects, the sub-artifacts, of the model-technology, information, and social context-need to be well aligned. There is no way to create such an alignment working toward "improved democracy" if the artifacts are designed in totally different ways and for completely different purposes. The EIU report shows that such a discrepancy is the case in many places. However, it also demonstrates that it is not all black and white. In many not fully democratic countries, there is ample room for improvement. While governments in such countries are not likely to change dramatically any time soon, there are many indications that important improvements in participatory processes can be made.

Let us look at one promising example from Uganda, a country firmly classified as authoritarian:

CIPESA (Collaboration on International ICT Policy in East and Southern Africa; cipesa.org) is a Ugandabased NGO that assists people in claiming their rights toward government. Corruption is widespread in the country, which ranks 149th of 180 countries in the Global Corruption Perception Index [Transparency International 2019]. Many government officials are subject to bribery. At times, they are not even available in the office to assist citizens in receiving the services they are entitled to by law. Citizens hesitate to complain, as the government is authoritarian. There are often no working ways to complain, let alone succeed in doing so. In this situation, CIPESA steps in as a mediator. Examples of projects where citizen participation is facilitated include the following.

Digital Government: Research and Practice, Vol. 1, No. 2, Article 17. Publication date: April 2020. 
The Women of Uganda Network (WOUGNET) works with Community Based Organizations and Voluntary Social Accountability Committees (VSACs) to empower women in use of ICT so as to enable them to play a part in monitoring service delivery in northern Uganda. Their mission is to help women in the country develop the capacity to use ICT as tools to share information and collectively address issues of community concern. Through the initiative, WOUGNET anticipates increasing external pressure on the leaders by empowering local citizens to expose corruption within their districts through use of ICT and the mass media platforms, thus causing a positive change in their districts' governance and service delivery performance [Wamala 2013].

Toro Development Network works with 15 rural advocacy forums and four local radio stations in western Uganda as hubs for information and knowledge sharing sourced through social media and mobile phones (TracFM SMS polling). Regular talk shows and content are designed to empower media practitioners and local citizens to advocate for and to monitor service delivery.

Transparency International Uganda (TIU) supports communities in northern Uganda to report and act on shortcomings in public health services delivery. TIU uses a toll-free call center, social media, and radio programmes to empower and promote community participation in monitoring health service delivery at health centers in northern Uganda. The project also empowers citizens, primarily voluntary accountability committees, to demand social accountability of health workers. Through a toll-free line, members of these communities and the community at large can report health service delivery challenges. Reports are verified through field visits and evidence gathering before being raised with the respective authorities for remedial action.

These three initiatives work in a similar manner: They enable citizens to monitor and report service delivery failures through the use of a mix of ICT. Each project has a core group of voluntary service delivery monitors spread throughout the villages in which the projects operate. They are trained in monitoring service delivery and in using ICT tools for social accountability purposes. They, in turn, mobilize other citizens and take a lead role in interfacing between citizens, the project implementers, and service providers. Some of the monitoring groups are provided with equipment such as cameras, mobile phones, laptops, and bicycles to facilitate their work.

Once a complaint is received, the project implementers take the initiative to establish its authenticity and then take up the matter with the relevant duty bearers to remedy it. There are also physical community meetings where the issues raised are discussed, and these also help project implementers to create cordial working relationships between the monitors and the duty bearers.

CIPESA's capacity building in civic agency has, during 2017-2019, included education for 1,300 individuals in Uganda and 860 in Kenya and Tanzania. Awareness raising through various channels, including radio, information materials, and bulk SMS, has reached an estimated 20 million citizens.

The complaints systems (crowdsourcing portals, SMS platforms, call centers, and public access centers) have received on average 700 reports per year in Uganda alone. Around $35 \%$ of the cases received through these media were investigated, referred to relevant authorities for remedial action, and followed up with feedback to individual reporters [Wakabi 2019].

In terms of the ISA model, the CIPESA work method includes an information artifact that provides the necessary anonymity between the people requiring a service and the officials providing it. The information exchange is facilitated by a technical artifact involving a set of cheap and easily accessible tools. While these tools have proven very useful, a necessary ingredient in the information flow is the human mediator. The government's failure to provide services is met not with conflict but rather by providing a "buffer" social artifact mediating between citizens and government in a way that makes for sustained cooperation.

However, the decline in democracy in general has also affected CIPESA. Uganda and many of its neighboring countries in East Africa (e.g., Tanzania, Burundi, South Sudan, and Kenya) are experiencing a rise in restrictions on civic space, principally manifested through the enactment of regressive legislation targeting civic activism and civil society organizations, violent crackdowns on demonstrations and arrest, threat of arrest, and intimidation of journalists. The online communication sphere has not been spared, with Uganda notably arresting 
and prosecuting a number of independent and critical social media users and making regulations that hamper Internet access and affordability, such as a daily tax on the use of social media platforms [CIPESA 2019].

\section{CONCLUSION}

This article has presented a view of democracy that involves not just the formal decision-making system but also the preconditions for it to function in ways that are compatible with the general notion of democracy and citizen participation. The basic reference was the EIU democracy index and the definition of citizen participation was in line with Almond and Verba [1963].

The ISA model was used to discuss the problem of democratic participation in a non-partisan way in terms of the technology used, the information flows, and the social systems in which technology and information are used to communicate.

The main conclusions are that the problems of democracy, from a global perspective, are more to do with the preconditions for democracy than with the formal decision-making system.

For digital democracy to be globally relevant it is necessary to find ways to make democratic improvements in countries who are flawed democracies or even authoritarian, because this is where most people in the world live and hence where improvement is most important.

Improvement is most likely to start small scale, in local contexts where there exists a sufficient amount of trust to make participation happen. An example of such an improvement was presented, the NGO CIPESA working from Uganda, covering a number of countries in the East Africa region.

There are also reasons to improve participation in "fully democratic" countries, and to show how this can take place, two cases from Sweden where conducive environments for participation were presented. The environments were created in different settings where issues with considerable political loading were discussed in professional contexts and without direct relation to, but considerable influence on, political decision making. Notably, in one case the initiative came from a government authority.

Democracy is not something you have but something you do. It grows from what people do every day. In the cases reported here, participation was improved only because some people decided to do something to change things. SALAR decided to hold a consultation, because a few people in the organization worked for that to happen and it was consistent with a current positive public sentiment toward participation. In Uganda, people in NGOs work for something they believe in and are financially supported by people in other countries who also believe in it and in the people who do the job. Democracy has to be earned every day by many people in every country. Technology can be of great help and make people achieve things they could not do before, but only in the hands of those people.

The research field of digital democracy can help by keeping an open mind to what democratic participation is about. It is not confined to the processed of formal democracy but is an important aspect necessary to consider in many contexts, including, for example, many processes often defined away as "digital government" and hence out of the scope for discussions of (digital) democracy.

\section{REFERENCES}

Gabriel Almond and Sidney Verba. 1963. Civic Culture: Political Attitudes and Democracy in Five Nations. Princeton University Press, Princeton, NJ.

Sherry Arnstein. 1969. A ladder of citizen participation. J. Am. Inst. Plan. 35 (1969), 216-224.

J. Åström. 2001. Should democracy online be quick, strong, or thin? Commun. ACM 44 (2001), 49-51. D0I : 10.1145/357489.357505

Joachim Åström. 2019. Citizen participation. In The Wiley-Blackwell Encyclopedia of Urban and Regional Studies. Anthony M. Orum (ed.). Wiley-Blackwell, Malden.

B. Barber. 1984. Strong democracy. In Participatory Politics for a New Age. University of California Press, Berkeley.

K. Blomberg, A. Anderxén Carlsson, L. Hagberg, Ó. Jonsson, L. Leissner, and M. Eriksson. 2017. Quality of life and trust among young people with narcolepsy and their families, after the pandemrix(R) vaccination: Protocol for a case-control study. BMC Pediatr. 17, 1 (2017), 183.

Digital Government: Research and Practice, Vol. 1, No. 2, Article 17. Publication date: April 2020. 
K. Blomberg, M. Eriksson, R. Böö, and A. Grönlund. 2019. Coping with narcolepsy after pandemrix® vaccination-Using the social media. F. Med. Internet Res. DOI : 10.2196/11419

CIPESA. 2019. The Shrinking Civic Space in East Africa. Retrieved from https://cipesa.org/?wpfb_dl=299.

EIU. 2018. Democracy index 2018: Me too? Political participation, protest and democracy. The Economist Intelligence Unit. Retrieved from http://www.eiu.com/Handlers/WhitepaperHandler.ashx?fi=Democracy_Index_2018.pdf\&mode=wp\&campaignid=Democracy2018.

A. Grönlund. 2001. IT, demokratin och medborgarnas deltagande (IT, Democracy, and Citizen Participation). Teldok, Stockholm. [In Swedish]

A. Grönlund and M. Hällgren. 2002. Internetval-succé eller fiasko? Försöket vid Umeå studentkår (Internet elections-Success or failure? The Umeå Student Union Trial). HumanIT, 4/2002.

Rob Kling, Howard Rosenbaum, and Steve Sawyer. 2005. Understanding and Communicating Social Informatics: A Framework for Studying and Teaching the Human Contexts of Information and Communications Technologies. Information Today, Medford, NJ.

Rob Kling. 2007. What is social informatics and why does it matter? Inf. Soc. 23, 4 (2007), 205-220. DOI : 10.1080/01972240701441556

A. Lee, M. A. Thomas, and R. Baskerville. 2015. Going back to basics in design science: From the information technology artifact to the information systems artifact. Inf. Syst. f. 25, 1 (2015), 5-21.

A. Lührmann, V. Mechkova, S. Dahlum, L. Maxwell, M. Olin, C. S. Petrarca, R. Sigman, M. C. Wilson, and S. I. Lindberg. 2018. State of the world 2017: Autocratization and exclusion? Democratization 25, 8 (2018), 1321-1340. DOI : 10.1080/13510347.2018.1479693

T. Ohlin and M. Hällgren. 2002. Internet voting in practice: The case of the umeå student union. E-Serv. F. 2, 1 (2002), 35-61.

C. Pateman. 1976. Participation and Democratic Theory. Cambridge University Press, 1976.

J. Richardson and J. Emerson. 2018. EDemocracy: An emerging force for change. Mapping the Ecosystem for Impact and Investment. Stanford Social Innovation Review. (https://ssir.org/articles/entry/edemocracy_an_emerging_force_for_change).

H. Simon. 1996. The Sciences of the Artificial (3rd ed.). MIT Press, Cambridge, MA.

SKL. 2019. Nationell handlingsplan för digitalisering av skolväsendet (National roadmap for digitalization of the school sector). SALAR, Swedish Association for Local Authorities and Regions. Retrieved from https://webbutik.skl.se/shop?funk=visa_artikel\&artnr= 7585-773-2. [in Swedish].

Transparency International (TI). 2019. Uganda's Corruption Perceptions Index. Retrieved from https://www.transparency.org/country/UGA.

W. Wakabi and Å. Grönlund. 2015. Enhancing social accountability through ICT: Success factors and challenges. In Proceedings of the International Conference for E-democracy and Open Government (CeDEM'11), P. Parycek, M. J. Kripp, and N. Edelmann (eds.), 5-6.

W. Wakabi. 2019. Wairagala wakabi, executive director of cipesa (personal communication, August 15, 2019).

C. Wamala. 2013. Empowering Local People and Communities to Monitor Districts Services Delivery through ICTs: Results and Lessons Learned. Retrieved from http://spidercenter.org/polopoly_fs/1.162451.1389618325!/menu/standard/file/Results\%20WOUGNET\% 20December\%202013.pdf.

Wikipedia. 2019a. Ethiopian Airlines Flight 302. Retrieved from https://en.wikipedia.org/wiki/Ethiopian_Airlines_Flight_302.

Wikipedia. 2019b. 2019 National Election Calendar. Retrieved from https://en.wikipedia.org/wiki/2019_national_electoral_calendar.

Received August 2019; accepted September 2019 